\title{
Why Integrity and not Coherence?
}

\author{
Gayane Gasparyan \\ Yerevan State Linguistic University
}

\begin{abstract}
$\mathrm{T}$ o answer the above question one should clearly determine what integrity is. Being of Latin origin and used to represent one of the textual parameters or categories, the term comes to denote wholeness. It reveals the interdependence and interaction of all parts of any utterance, both oral and written, bringing to its completeness.

Integrity is a term mostly used by Russian linguists to define one of the constituent components of a whole text, a category which comes to make the text coherent. It is considered one of the most powerful textual categories which leads to the unification of all parts of an utterance and reveals the author's conceptual approach towards the reality described in the text.

While speaking about the category of integrity I. Galperin mentions that it shouldn't be confused with the category of cohesion (Galperin 1981). He defines cohesion as a certain type of grammatical, lexical, semantic linkage between separate sentences, supraphrasal unities and other independent parts of the text. According to his definition of integrity the latter does the same but in another way, by means of different logical and associative issues which reveal the interrelation and interdependence of different portions of factual information. The same definition may be found in "Interpretation of Text" by V. Kukharenko (1988).

Thus, basically I.Galperin and his followers describe cohesion and integrity in similar terms. According to them both categories come to link the portions of the text and ensure the successive comprehension of factual information. Though, while speaking about integrity they single out the so-called integrity core which may be placed in any part of the text and accumulate all the information, either factual or conceptual. The chief idea/concept of the text, according to their definition, is located in this core, and the successive development of the information becomes a double-sided process: it may be centripetal, on the one hand, and centrifugal on the other. It means that the information, mainly the conceptual one, either acquires the power of progressive development, moving towards this integrity core, or withdraws from it and spreads all over the text. They state further that the integrity core accumulates mostly conceptual, but not factual information within itself. Consequently, the difference between cohesion and integrity becomes apparent: cohesion forces the successive development of factual information, whereas integrity reveals the process of unification of all the conceptual information to achieve wholeness and completeness of the text. Thus, cohesion is considered to be a logical category, whereas integrity is a psychological one.

Consequently another question may occur: why cohesion is a logical and integrity a psychological category. The answer actually can be found within the course of discourse analysis of a text based on its communicative value and interactants' cooperation in a certain communicative situation. If a text is an integral part of such a situation located in between two communicants, then cohesion absolutely depends on the author of the utterance as it is arranged by him/her to foster the logical-successive development of the events
\end{abstract}


described in the text. Cohesion can actually be considered a logical category because it is "visible", explicit due to the language means it is created by. On the other hand, integrity created by the author becomes relatively independent of him/her as much depends on the recipient's ability to perceive correctly whatever the author's intention is. Thus, the category of integrity becomes a psychological one, as it is not quite easily found in the text, it is rather implicit and depends on the interpretative perception of the recipient, as the one who sends the message is not absolutely sure, whether it will be perceived and interpreted by the one who receives it accordingly in the way he/she desires to.

Integrity depends on comprehension and mutual understanding, it lies outside the text and creates certain psychological interconnection between the communicants. This communicative situation viewed as a certain type of discourse creates interdiscoursive relations between the author, the text and the recipient. All of these together become a sort of constituents of a communicative act where the text is the chief linking point between the communicants.

Thus, both cohesion and integrity create inside-the-text and outside-the-text strategies: logical links within the frames of the text by means of cohesion and psychological relations between the communicative situation and the text itself.

The term integrity is not so much used in other theories. Instead, coherence comes to indicate different issues which determine the category of integrity. The terms cohesion and coherence, or local and global cohesion are more often used to describe the properties of an utterance in discourse analysis and text linguistics.

For all those who do not know the difference between cohesion and coherence, the two terms seem very much alike because of their pronunciation, semantic significance and communicative directives. But for those who know the difference they are absolutely different in their pragmatic determination and functioning values within the frames of a text/discourse. They both are described as integral parameters of any text/discourse without which the latter cannot exist. They both are rather disputable linguistic phenomena as there does not exist a finalized and properly distinguished approach towards them.

Some modern approaches are mainly based on M.A. Halliday's and R. Hasan's (Halliday, Hasan 1976) taxonomy of cohesion. According to them the surface structure of the text is more important for indicating its cohesive means, hereby sentence becomes the measurable unit of discourse. But the opponents of this viewpoint seek to prove that the focus on sentence makes the deep sense of text cohesiveness incomplete.

Thus, according to U. Connor's definition cohesion is determined by the use of explicit linguistic devices to signal relations between sentences and parts of texts. Among the cohesive devices those words and phrases are mentioned, which help the reader associate previous statements with subsequent ones (Connor 1996). Consequently, coherence acquires semantic value and is absolutely based on semantic relationships. This is the reason why, while speaking about coherence, T.A. van Dijk focuses mainly on semantic aspect. He keeps to the viewpoint that coherent texts make sense to the reader, that coherence is a semantic property of discourse formed through the interpretation of each individual sentence relative to the interpretation of other sentences, with "interpretation" implying interaction between the text and the reader (Van Dijk 1988). 
Thus, cohesion is usually regarded as a clearly linguistic means that links different sentences, parts and sections of a text/discourse, whereas coherence is actually a pragmatic concept that forces logical thinking. Therefore cohesion depends upon the author's will and desire how to create the logical succession and interdependence of separate facts and portions of information in text/discourse. Being an absolutely pragmatic notion coherence at a higher degree depends upon the recipient/reader/listener, upon his/her background knowledge in its broadest sense.

From this particular viewpoint integrity may be regarded as a process of unification of all the portions of factual information within the course of cohesion that ensures the progressive development of conceptual information within the course of coherence. It leads to the consolidation of an informative and semantic environment inside (cohesion) and outside (coherence) the text and achieves the target tasks any "text - discourse" relations perform: correlation - wholeness - completeness. Thus, cohesion comes to reveal the author's attitude towards the facts and their correlation within the text, whereas coherence exposes the author's attitude towards the actual reality and the facts described in the text. They both may be described in terms of local and global coherence suggested by T. Van Dijk and V. Kinch (1988). Anyhow, the terms used to denote the inside and outside relations between the facts described in the text and the reality existing around the text (the out-of-text environment) may be different and numerous in number, though they refer to the same phenomena and determine the same certain types of correlation within the course of their functioning. And whatever is mostly important, they expose different types of attitude on both author's and reader's/listener's part.

Very briefly S. Thornbury describes these categories in the following way: "a text is cohesive if its elements are linked together. A text is coherent if it makes sense. It should be clear that these are not the same thing. That is, a text may be cohesive (i.e. linked together), but incoherent (i.e. meaningless)" (Thornbury 2005).

As seen, once again cohesion is viewed as an inside-the-text purely structural category, whereas coherence is an outside-the text logical category. This is why when we speak about the "meaning" of a text, we do not absolutely mean the factual information developing within the frames of the text, we mostly mean the author's conceptual approach towards the reality perceived by him/her, reconstructed in his/her personal way and reproduced in his/her individual manner. Hence the actual representation of the world depends upon the author on the one hand when it is reflected in the text/discourse and the recipient on the other, when a double-phase perception is brought forth. The latter means that the actual reality is first perceived by the author, secondly reflected in his/her utterance and then both the outside-the-utterance and inside-the-utterance reality is accordingly perceived by the recipient. Coherence in this case becomes a key aspect of discourse comprehension, it forces the recipient's interpretative and evaluative perception. But if the interpretative and evaluative aspects of the recipient's perception do not operate, the utterance loses its meaningfulness and purposefulness and becomes incoherent. The communication between the interactants becomes ineffective due to their misunderstanding of the situation. The same may be applied to the text as a certain type of utterance. If the reader's interpretative perception does not lead to evaluative 
partnership between the author and the reader, the author's intention remains unrecognized and the text becomes incoherent (meaningless) for the reader. He/she will easily single out the cohesive markers within the text, but won't grasp its sense because will not imagine the context outside the text. The reader will not be able to realize the conceptual information and the text will remain incoherent for him/her.

In this case one more question may occur: doesn't coherence lead to integrity? Yes indeed, it really does, as it performs the same function - it determines wholeness and completeness of the text. The discourse creating power of both categories (coherence and integrity) makes them very much alike and puts them close within the course of text interpretation. Hence they both may be regarded as one and the same aspect of text/discourse comprehension, a "container" of author - reader mutual understanding in the course of their intercommunication.

\section{References:}

1. Galperin, I.R. (1981) Tekst kak objekt lingvisticheskogo issledovania. M.: Nauka.

2. Kukharenko, V.A. (1988) Interpretacia teksta. M.: Prosveschenie.

3. Halliday, M.A., Hasan, R. (1976) Cohesion in English. London: Longman.

4. Connor, U. (1996) Contrastive Rhetoric: Cross-cultural Aspects of Second-Language Writing. Cambridge: Cambridge University Press.

5. Van Dijk, T.A. (1988) Text and Context: Explorations in the Semantics and Pragmatics of Discourse. London: Longman.

6. Van Dijk, T.A., Kinch, V. (1988) Strategii ponimania svjaznogo teksta. // Novoe v zarubezhnoj lingvistike XXIII. / Kognitivnie aspekti jazika. M.: Progress.

7. Thornbury, S. Methodology: Coherence and Cohesion. < http://www.onestopenglish.com/ support/ask-the-experts/methodology-questions/methodology-coherence-and-cohesion/154867.article>

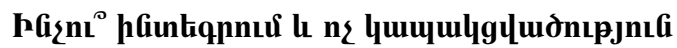

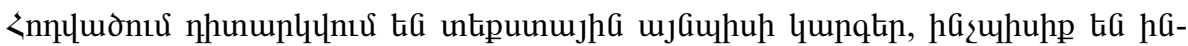

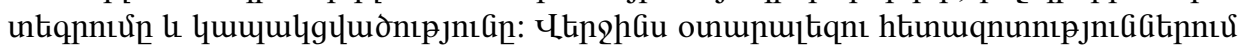

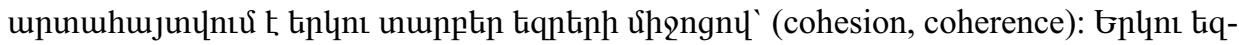

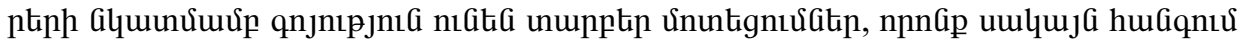

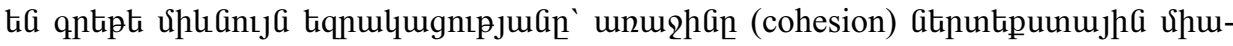

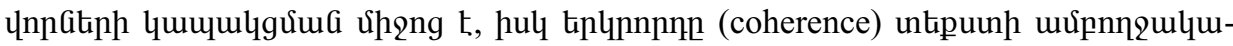

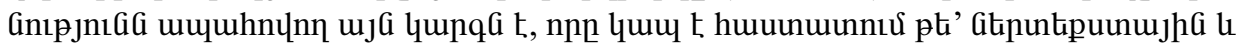

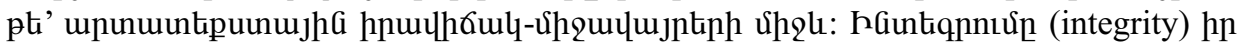

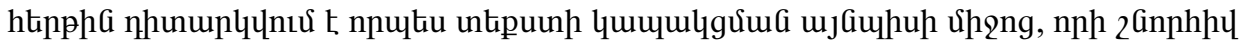

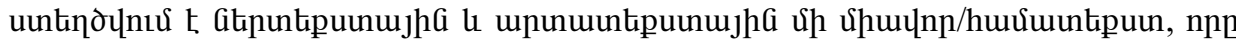

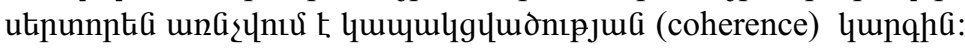

